equipment and supplies have to be imported and large stocks must therefore be carried. A rear access road leads up to the door of this area, and there is an unloading ramp leading into a wide passage-way where goods may be unpacked protected from the weather and predators.

The south wing contains the agricultural botany and agricultural zoology teaching laboratories, and there is a smaller laboratory for teaching animal physiology, one for advanced students and a number of small laboratories for research.

An important adjunct to the central and research building is the University farm, Kabanyolo, 11 miles from Makerere College and close to the Empire Cotton Growing Corporation's main research centre at Namulonge.

We have been fortunate in that we have been able to settle in the new School of Agriculture a few months before the opening of the course for the B.Sc. (Agriculture) degree in special relation with the University of London. As the Faculty develops, we hope that we shall be a centre not only for teaching but also for research, attracting workers from East Africa and beyond. We have undoubtedly been given the physical conditions in which these may proceed.
Margaret A. Keay

\title{
CONSERVATION OF NATURE IN SOUTH-EAST ENGLAND
}

\begin{abstract}
CONFERENCE on "Conservation of Nature in South-east England", convened by the Southeastern Union of Scientific Societies, was held in the rooms of the Zoological Society of London on April 12, under the chairmanship of the Earl of Cranbrook.

The first paper was on "The Invertebrate Fauna of the Chalk Country and its Conservation". Mr. John Sankey commenced by commenting on the general lack of knowledge of invertebrate ecology, which was surprising when one considers the tremendous amount of collecting which must have been done in the chalk country of south-east England. It is a great pity that collectors have not published more records. He said that before one can speak of the conservation of animals it is necessary to know which animals we want to conserve and this needs a detailed survey of the invertebrate life of chalk country. Like a great deal of present-day synecological work a team of specialists is required for such an undertaking. Even when comprehensive lists are available there still remains the task of sorting, collating and
\end{abstract} interpreting the information.

Since all animals are dependent on the vegetation and the plants are dependent upon the soil, rock, climate and other physical factors, it follows that the zoological ecologist should also have at least a working knowledge of these subjects. Finally, he must be able to assess the effects of biotic factors in the environment. To anyone who has collected invertebrate animals in our chalklands the rich variety and frequent abundance of many species must be apparent. Such a type of fauna lends itself to fairly effective sampling methods. The proper approach would seem to be in the choice of a number of typical sample areas on the chalk. It will be necessary to consult the botanists when choosing places for intensive study, though one can be entirely dependent on what they may describe as areas of typical chalk country because animals, unlike plants, move about and they often occur quite commonly in places which have been disturbed and which botanically are not typical of the chalk. If, by sampling and listing, we can determine which are the richest and most typical areas of the chalk invertebrate fauna, then we have a basis for conservation of this fauna. Mr. Sankey concluded by saying that it is only through a sound knowledge of the ecology of animals that their conservation can be successfully effected.

Mr. Maxwell Knight spoke upon "The Vertebrates of Frensham Ponds and Romney Marsh". He said he would like to approach the question as if it were the point of view of the animals themselves. If the animals were to be protected, the protection of the environment was necessary. Using the natterjack toad as an example, he said that whereas a few years ago hundreds were present at the large pond at Frensham, to-day, owing to human interference, none existed. Some had become established at the small pond but commercial interference, including boating and fishing, threatened their extinction. The haunt of the natterjack, the reed marshes, had been cleared. The removal of the reeds changed an environment essential for their existence, for the breeding period was a long one, spreading from April to June, so adults, young and tadpoles were together at the same time; at others tadpoles and spawn were together. $\mathrm{He}$ next spoke of the sand lizard and its curious distribution. One type, with subdued small markings, occurs in the south as far as Dorset; then there was a belt across the country from which they are absent until Lancashire is reached, when a type with pronounced blotches occurs. At Frensham within a few miles of each other both types exist. The colonies move from year to year, in hot years tending to approach the ponds where the dew helps to increase the number of spiders upon which they feed.

The smooth snake is becoming increasingly rare in the area, but it may be more widely distributed than is supposed for it does not bask in the sun but either goes to earth or seeks cover under large stones. The conservation of an area which would permit the breeding of small rodents upon which it feeds is desirable.

Mr. Maxwell Knight concluded by speaking of the introduction of a few pairs of marsh frog during 1935 into Romney Marsh. It became sufficiently numerous within a few years to have a question asked in the House of Commons regarding its nuisance. Recently there has been a considerable reduction in numbers, possibly due to the fall in the freshwater shrimp population. The question of the desirability of protecting an introduced animal was discussed. The effect of its introduction upon the water population was the disappearance of the common frog and toad, the newt and some of the dragonflies. On the beneficial side it was said that there was an absence of mosquitoes since the introduction of the marsh frog.

Dr. Francis Rose chose as his subject "Possible Nature Reserves in Kent, Sussex and Surrey: a Botanical Ecologist's Viewpoint". He said he wished to deal with his subject under two headings, the plant communities and flora of the Wealden counties; and nature conservation in this region. 
The Weald of south-east England, with its partly encircling chalk of the North and South Downs and adjacent coastal areas, is one of the richest parts of Britain both in its range of plant communities and habitats, and the number and variety of plant species. This is due to a number of causes, some very complex; but, to present a simplified picture, we can say that three main features are responsible: (1) The wide range of geological strata outcropping in the region in successive belts, giving rise to a great variety of soil types ; (2) the proximity of the region to the Continent of Europe, with the result that, particularly in Kent, many Continental species are represented; (3) the rather humid oceanic climate of the dissected plateau of the Weald, which together with the still more oceanic microclimate of the deep, sheltered valleys has enabled a markedly Atlantic floristic element to extend.

The area has long been affected by the diverse activities of man and this has led, among other things, to the development of such interesting plant associations as heathland, valley bog and chalk grassland. On the other hand, the primeval forest persisted until comparatively recently in the Weald. Now the flora and fauna of this unique region are threatened as never before by the present enormous pressure on all available land for a wide range of purposes. This pressure on land is inevitable, but with careful planning it is possible to set aside small areas of land as nature reserves, to provide both living examples of plant and animal communities and outdoor laboratories for scientific research on these communities. Dr. Rose then spoke of the woodlands of the Weald, saying there are so many types that time would not permit a discussion on them. The Nature Conservancy has already a reserve of coppice-with-standards woodland on the Weald clay, but fine examples of the more natural 'high forest' type, with oak and beech, still exist in West Sussex, and here preservation of a sample is badly needed. On the coastline there are the magnificent shingle beaches of Dungeness, fine estuarine salt marshes, the cliffs and the sand-dunes of Sandwich with their incredibly rich flora. To summarize, very few species have as yet been actually lost as the result of the modern developments and certain rarities have reappeared, but this happy state of affairs is unlikely to last. Properly managed local nature reserves are an urgent noed and, if we are to preserve these wonderful communities, the formation of local trusts is essential.

Dr. J. T. Doney, speaking on "Conservation in Hertfordshire", directed attention to the general deterioration of parts of the area, especially of parklands no longer receiving the necessary attention and rapidly becoming derelict sites. Commons still exist and, if negotiations could be successfully carried out, would make good nature reserves. He stressed the need of co-operation with the local and county authorities and said that the detailed county plans broadly met the wishes of his committee. The Hertfordshire County Council needed support on the matter of conservation and the Trust could help with advice upon the preservation of verges which were disappearing, partly as the result of ribbon development. The list of suitable sites for reserves should be carefully reconsidered, ensuring the reservation of places of ecological importance rather than those of pleasant surroundings only. $\mathrm{He}$ considered that rather than sites for the preservation of a rare species, those possessing a rich and varied flora and fauna should be recommended.
A symposium on "Naturalists Trust: their Contribution to Nature Conservation" was held during the afternoon.

Mr. Ronald Hickling (Leicestershire) dealt with the structure and nature of a Naturalist Trust. It should be a separate organization with a singleness of purpose. Its purpose was too fundamental for it to be a department of a natural history society, although all naturalists should be brought into the movement of conservation. It was essential that other interests should be represented on a Trust, particularly the Lord Lieutenant of the County and the Planning Officer. The Trust should be a corporate body, registered as a limited company, thus being able to own property and to enter into agreements. With the use of discretion, the cost of the formation of a Trust should be less than $£ 100$, and it should be established as a charity working for the benefit of society.

Mr. R. E. Smith (Lincolnshire) spoke next. He emphasized that the increased pace of development gave the opportunity for increased local voluntary action. A Trust should attend not only to safeguarding but also make recommendations of suitable sites for reservation, co-operating with the local planning officers who could designate the areas. It should establish good relations with the Ministry of Agriculture and the Forestry Commission. Where possible, suitable areas should be purchased, otherwise they could be leased by agreement with either private owners or public bodies. Statutory bodies should be influenced to use the powers given to them by the 1949 National Parks Act. Management of a reserve, when funds are available, should be' by a paid warden; if this is not possible, voluntary help should be enlisted. The erection of huts for the warden and for use as laboratories is desirable. The Trust should offer assistance in the management of existing Nature Conservancy reserves.

The closing address was given by Dr. Max Walters (Cambridgeshire). He wished the organization to be upon a county basis rather than a city as it tends to be in Cambridge. Publicity was an important part of the work of a Trust, contacts with schools being necessary. He would welcome co-operation with both city and county educational authoritios for the distribution of leaflets and the arrangement of evening meetings and excursions for teachers of biology. Talks should be arranged for all local organizations and full use made of the local Press by contributions and letters.

There was a multiplicity of organizations dealing with the problem and a Trust would not only simplify the complexity but would also clarify and co-ordinate the various points of view and aims.

During the discussion following, a landowner, while warmly supporting the movement, spoke of the financial difficulties experienced in the management of his property and welcomed advice upon how help could be given by owners to conservation in such circumstances.

It was announced that arrangements are in hand for the formation of four County Trusts within the southeastern area: Essex, Kent, Surrey and Sussex. A motion was carried "That an advisory committee be formed to assist and advise those areas which may wish to proceed with the formation of a Naturalists Trust". A committee of five was elected with Mr. Frank Edwards, 53 The Drive, Shoreham-bySea, Sussex, as secretary, to whom all communications should be addressed.
F. J. EPPS 